\title{
Radiation Testing of Optical and Semiconductor Components for Radiation-Tolerant LED Luminaires
}

\author{
Alessandro Floriduz, Member, IEEE, and James D. Devine, Member, IEEE
}

\begin{abstract}
An irradiation campaign was conducted to provide guidance in the selection of materials and components for the radiation hardening of LED lights for use in CERN accelerator tunnels. This work describes the effects of gammarays on commercial-grade borosilicate, fused quartz, polymethylmethacrylate, and polycarbonate samples up to doses of $100 \mathrm{kGy}$, to qualify their use as optical materials in rad-hard LED-based luminaires. In addition, a $\mathrm{Si}$ bridge rectifier and a $\mathrm{SiC}$ Junction Barrier Schottky diode for use in power supplies of rad-hard LED lighting systems are tested using $24 \mathrm{GeV} / c$ protons. The physical degradation mechanisms are discussed for each element.
\end{abstract}

Keywords-Radiation testing, lighting system, fused quartz, borosilicate, polycarbonate, polymethylmethacrylate, SiC Schottky diode, silicon diode bridge, defects, colour centres.

\section{INTRODUCTION}

$\mathbf{G}$ ENERAL lighting in CERN accelerator tunnels and experimental caverns is currently provided by fluorescent tubes with wire-wound ballasts, and the present emergency lighting system comprises a combination of incandescent and low-pressure sodium discharge lamps. However, luminaires using these technologies are now obsolete and cannot be purchased any more on the European market, and thus have to be replaced by LED lights having much higher efficiency. Nevertheless, adoption of LED-based luminaires in radiation environments like high-energy physics accelerator facilities poses several challenges due to the radiation effects on semiconductor components [1]; indeed, we recall that, on the walls of a typical section of CERN accelerator tunnels, the annual radiation levels can exceed a $1 \mathrm{MeV}$ neutron equivalent (neq) fluence in $\mathrm{Si}$ of $5 \times 10^{12} \mathrm{n} / \mathrm{cm}^{2}$ and a dose of $1 \mathrm{kGy}$ [2]. Irradiation of prototype LED lights for radiation environment has been carried out previously, results of which are summarized in [1]. Following the encouraging outcome of these preliminary tests, a dedicated irradiation campaign has been performed to study the effects of radiation on each individual component to be included in a radiation-tolerant LED lamp (see Fig. 1), namely: $i$ ) the diodes for the power supply unit (consisting of a simple bridge rectifier), ii) the plastic lenses and glass windows, and iii) the GaN-based white LEDs. This paper summarizes the results on irradiation tests of the first two components; the behaviour of irradiated highpower white GaN LEDs is available in [3].

In this work, we tested under $\gamma$-ray irradiation samples of borosilicate (BS), fused quartz (FQ), polymethylmethacrylate

A. Floriduz and J. D. Devine are with the Electrical Network Projects Section of the Electrical Group, Engineering Department (EN-EL), CERN (European Organization for Nuclear Research), CH-1211 Geneva 23, Switzerland (email: alessandro.floriduz@alumni.cern, james.dilwyn.devine@cern.ch).
(PMMA) and polycarbonate (PC). We chose to study these materials as they are commonly used in commercial luminaires: glass (BS or FQ) for protective windows, and plastic (PMMA or PC) for secondary optics. Reports on the irradiation of these materials already exist, but tests under the same irradiation and annealing conditions were required to better compare the amount of radiation damage induced to the various materials, so as to identify the most resistant ones.

In addition, a $\mathrm{Si}$ bridge rectifier and a $\mathrm{SiC}$ Junction Barrier Schottky (JBS) diode have been tested; irradiation was done using $24 \mathrm{GeV} / c$ protons instead of $\gamma$-rays, displacement damage being the dominant degradation mechanism in diodes. A Si diode bridge sharing the same technology as the selected one had already been tested against irradiation up to a $1 \mathrm{MeV}$ neq fluence of $8 \times 10^{13} \mathrm{n} / \mathrm{cm}^{2}[4]$; in the present work, the selected Si diodes were studied under even higher fluences. A SiC JBS diode was characterised for comparison and also because no irradiation of $\mathrm{SiC}$ JBS diodes with high-energy protons has so far been reported.

\section{COMPONENTS UNDER TEST}

\section{A. Optical components}

Samples of borosilicate (BS), fused quartz (FQ), UVgrade polymethylmethacrylate (PMMA), and polycarbonate (PC) have been tested against $\gamma$-ray irradiation. The samples have been provided by Goodfellow Cambridge Ltd. (UK); manufacturer part references are: LS475409/7, LS475409/3, LS475409/12, LS475409/13 for BS, FQ, PMMA, and PC samples, respectively. All samples were in form of polished disks with diameter of $40 \mathrm{~mm}$ and thickness of $3 \mathrm{~mm}$ (except BS and PMMA samples, having thickness of 3.3 and $3.1 \mathrm{~mm}$ respectively). All materials under test are commercial-grade and not specifically produced for use in radiation environment.

\section{B. Diodes}

Silicon bridge rectifiers and SiC Junction Barrier Schottky (JBS) diodes have been characterized against displacement damage using $24 \mathrm{GeV} / c$ protons, to qualify their use in rad-hard AC/DC power supplies for LED lights. The Si diode bridge under test is a Vishay B380C1000504H glasspassivated single-phase bridge rectifier in a WOG package, rated $1 \mathrm{~A}$ in average forward current and $600 \mathrm{~V}$ in maximum repetitive peak reverse voltage. It shares the same technology as the Vishay GBU8K diode bridge [5], [6], which has been previously tested against $1 \mathrm{MeV}$ neq fluences up to $8 \times 10^{13} \mathrm{n} / \mathrm{cm}^{2}[4]$; for this reason, it was selected as a candidate component. Two types of $4 \mathrm{H}-\mathrm{SiC}$ JBS diodes have also been tested: STPSC10H065D and STPSC10H12-Y diodes 


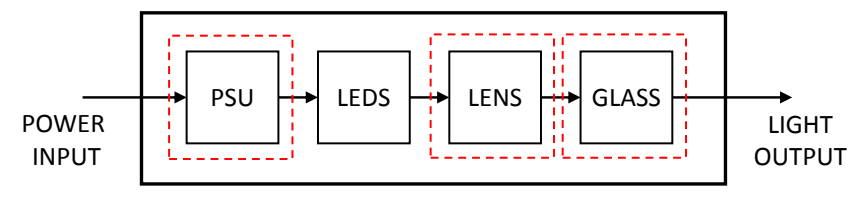

Fig. 1. Block diagram model of an LED luminaire, which comprises a power supply unit (PSU) feeding a string of white LEDs; it also includes plastic lenses for improved light distribution and a glass window for protection reasons. The response to radiation of the components highlighted in red is illustrated in the present work.

from STMicroelectronics, rated $650 \mathrm{~V}$ and $1.2 \mathrm{kV}$ in maximum repetitive peak reverse voltage, respectively; they are both rated for $10 \mathrm{~A}$ average forward current. More information on their device structures is available in [7]. The TO-220 package variants were used to facilitate testing.

\section{IRRADIATION CONDITIONS}

\section{A. $\gamma$-ray irradiation}

$\gamma$-ray irradiation of optical components was performed at Ionisos (Dagneux, France) [8], using a ${ }^{60} \mathrm{Co}$ source. Irradiation was done in air, at room temperature and atmospheric pressure. Four different target doses were specified: 2, 25, 50 , and $100 \mathrm{kGy}$; the actual values reached (as measured by radiochromic dosimeters) are respectively $2.5,28.5,58.2$, and $113.1 \mathrm{kGy}$. For the sake of brevity, we will make reference to the nominal values in the remainder of this paper. The doses are specified with respect to water (i.e. in $\mathrm{kGy}\left[\mathrm{H}_{2} \mathrm{O}\right]$ ). Table I illustrates the number of samples tested at each dose. During irradiation, the samples were contained in stainless steel perforated baskets. Irradiation of samples with target dose of $2 \mathrm{kGy}$ was performed through 5 complete turns on a secondary tray conveyor around the ${ }^{60} \mathrm{Co}$ source, at a dose rate comprised between $0.5-1 \mathrm{kGy} / \mathrm{h}$. Samples with 25 , 50, and $100 \mathrm{kGy}$ target doses were irradiated statically (i.e. placed on metallic shelves facing the source), at average dose rates of $0.46 \mathrm{kGy} / \mathrm{h}, 0.6 \mathrm{kGy} / \mathrm{h}$, and $0.58 \mathrm{kGy} / \mathrm{h}$, respectively. Irradiation of samples with the highest target doses started first, so that irradiation at all doses finished simultaneously, avoiding different annealing times for different target doses. The irradiated samples were stored at room temperature, and were all characterized within 50 to 52 hours from completion of irradiation.

TABLE I

NUMBER OF SAMPLES IRRADIATED PER DOSE

\begin{tabular}{ccccc}
\hline Material & $2 \mathrm{kGy}$ & $25 \mathrm{kGy}$ & $50 \mathrm{kGy}$ & $100 \mathrm{kGy}$ \\
\hline BS & $1 \mathrm{pc}$. & $1 \mathrm{pc}$. & - & $1 \mathrm{pc}$. \\
FQ & $1 \mathrm{pc}$. & $1 \mathrm{pc}$. & - & $1 \mathrm{pc}$. \\
PMMA & $4 \mathrm{pcs}$. & $4 \mathrm{pcs}$. & $4 \mathrm{pcs}$. & $4 \mathrm{pcs}$. \\
PC & $4 \mathrm{pcs}$. & $4 \mathrm{pcs}$. & $4 \mathrm{pcs}$. & $4 \mathrm{pcs}$. \\
\hline
\end{tabular}

\section{B. $24 \mathrm{GeV/c}$ proton irradiation}

Irradiation of samples of $\mathrm{Si}$ and $\mathrm{SiC}$ diodes was done at IRRAD facility (CERN) [9], using a $24 \mathrm{GeV} / c$ proton beam having a nominal gaussian profile with a FWHM of $1.2 \times 1.2 \mathrm{~cm}^{2}$. The actual proton fluence was determined by measuring the activation of thin aluminium foils placed in front of the samples during irradiation. A fluence of $24 \mathrm{GeV} / c$ protons can be converted into a $1 \mathrm{MeV}$ neq fluence providing the same non-ionising energy loss in silicon through the factor of $0.58[10]$. Irradiation was done at room temperature and atmospheric pressure. The samples were not powered while irradiated (passive test). Two batches of both $\mathrm{Si}$ and $\mathrm{SiC}$ diodes were irradiated; the target and actual fluences are collected in Table II Each batch comprises 5 diodes, except batch \#1 of Si diodes, which included only 3 units. After irradiation, the diodes were stored at ambient temperature. Measurements of irradiated diodes were taken only upon authorisation of the irradiation facility personnel, when the residual activation of the samples was acceptably low. The time before measurement (i.e. annealing time) for batches \#1 and \#2 of Si diodes was 6 and 5 days, respectively; for $\mathrm{SiC}$ diodes, it was 20 and 38 days, respectively. Radiation damage in $4 \mathrm{H}-\mathrm{SiC}$ is known to be thermally stable at room temperature [11] and should not be affected by the longer annealing period, although some form of recovery (associated to unstable radiation-induced defects) may not be excluded [12].

TABLE II

IRRADIATION FLUENCES OF SI AND SIC DIODES

\begin{tabular}{cccc}
\hline $\begin{array}{c}\text { Device } \\
\text { under test }\end{array}$ & $\begin{array}{c}\text { Target 24 GeV/c } \\
\text { fluence }\end{array}$ & $\begin{array}{c}\text { Actual 24 GeV/c } \\
\text { fluence }\end{array}$ & $\begin{array}{c}\text { Actual } 1 \mathrm{MeV} \\
\text { neq fluence in Si }\end{array}$ \\
\hline $\begin{array}{c}\text { Si diodes } \\
\text { (batch \#1) }\end{array}$ & $8 \times 10^{12} \mathrm{p} / \mathrm{cm}^{2}$ & $9.5 \times 10^{12} \mathrm{p} / \mathrm{cm}^{2}$ & $5.5 \times 10^{12} \mathrm{n} / \mathrm{cm}^{2}$ \\
$\begin{array}{c}\text { Si diodes } \\
\text { (batch \#2) }\end{array}$ & $3 \times 10^{14} \mathrm{p} / \mathrm{cm}^{2}$ & $2.4 \times 10^{14} \mathrm{p} / \mathrm{cm}^{2}$ & $1.4 \times 10^{14} \mathrm{n} / \mathrm{cm}^{2}$ \\
$\begin{array}{c}\mathrm{SiC} \text { diodes } \\
\text { (batch \#1) }\end{array}$ & $10^{13} \mathrm{p} / \mathrm{cm}^{2}$ & $1.2 \times 10^{13} \mathrm{p} / \mathrm{cm}^{2}$ & $7 \times 10^{12} \mathrm{n} / \mathrm{cm}^{2}$ \\
$\begin{array}{c}\mathrm{SiC} \text { diodes } \\
\text { (batch \#2) }\end{array}$ & $2 \times 10^{14} \mathrm{p} / \mathrm{cm}^{2}$ & $1.9 \times 10^{14} \mathrm{p} / \mathrm{cm}^{2}$ & $1.1 \times 10^{14} \mathrm{n} / \mathrm{cm}^{2}$ \\
\hline
\end{tabular}

\section{EXPERIMENTAL RESULTS}

\section{A. Optical components}

Transmission spectra of all samples of optical material were recorded before and after irradiation using a Perkin-Elmer UVVIS Lambda 650 spectrophotometer equipped with a $150 \mathrm{~mm}$ integrating sphere in the range $300-800 \mathrm{~nm}$ (only for quartz samples: 200-800 nm). Figure 2 illustrates the transmission spectra before and after $\gamma$-ray exposure. Equivalent results were obtained for all PMMA and PC samples irradiated to the same dose, so data relative to only one sample per dose is presented for these materials.

Before irradiation, transmittance of BS is $>90 \%$ (see Fig. 2a) until the UV cut-off edge at $335 \mathrm{~nm}$ [13], [14]. Upon increasing dose, two strong absorption bands located near $330 \mathrm{~nm}$ and $475 \mathrm{~nm}$ appear; these bands have been previously attributed to boron oxygen hole centres [15] (each centre is given by a hole trapped on a bridge oxygen structure with $\left.\left[\mathrm{BO}_{4}\right]^{-}\right)$. The large increase of absorption in the UV-blue portion of the spectrum leads to the darkening of BS samples (see Fig. 3a). 


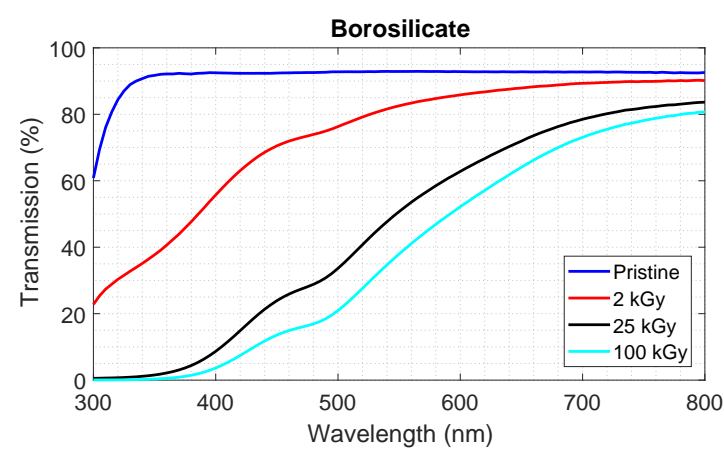

(a)

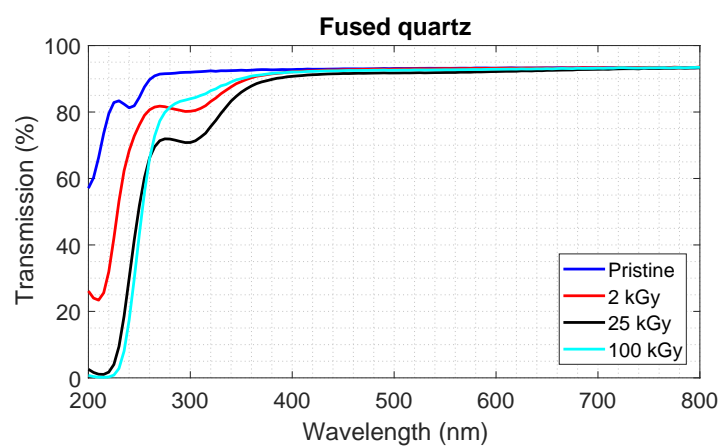

(b)

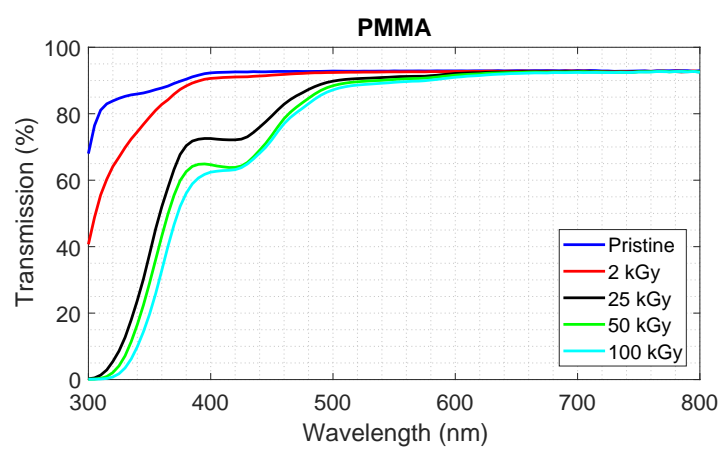

(c)

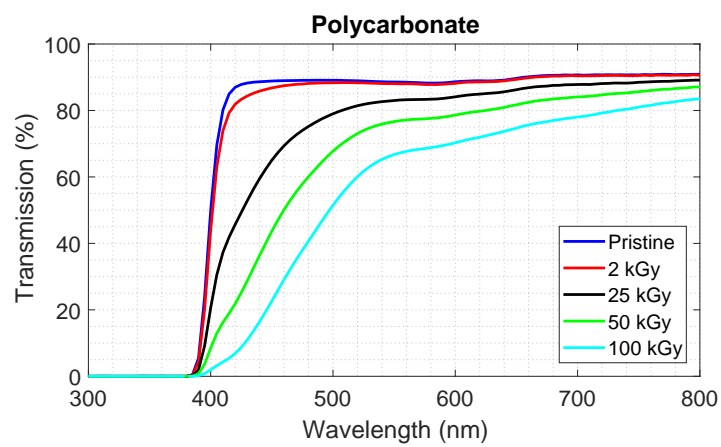

(d)

Fig. 2. Transmission spectra before and after $\gamma$-ray irradiation of samples of: (a) borosilicate, (b) fused quartz, (c) PMMA, (d) polycarbonate.

All samples of FQ before irradiation exhibit high transmittance $(>90 \%)$ until $260 \mathrm{~nm}$ (see Fig. 2b). Before irradiation, an absorption band located at $240 \mathrm{~nm}$ is clearly apparent, which we identify with the $B_{2} \beta$ band due to Ge oxygen deficient centres (GeODC) [16], [17]; this band precedes the UV cut-off edge, occurring at values close to those reported in literature for other samples of FQ [16], [17]. After irradiation, two new absorption bands emerge in the UV: the first at $\sim 210 \mathrm{~nm}$, the second at $300 \mathrm{~nm}$. The first band is attributed to the $\mathrm{E}^{\prime}$ centre (Si dangling bond $\equiv \mathrm{Si} \cdot$ ) [16], [17]; with increasing dose, absorption at $\mathrm{E}^{\prime}$ centres increases steadily, and slightly shifts to longer wavelengths. The origin of the absorption band at $300 \mathrm{~nm}$, referred to in literature as the $B_{1}$ band, is still unclear [16], [17], although it is thought to be formed from the conversion of the $B_{2} \beta$ band: the proposed mechanism is that a GeODC loses an electron due to irradiation creating a centre absorbing at $300 \mathrm{~nm}$ [16]. It has been demonstrated in previous works [16], [18] that the emergence of the $B_{1}$ band upon irradiation occurs only in FQ, and not in crystalline quartz or synthetic fused silica. Absorption at this band increases with increasing dose up to $25 \mathrm{kGy}$; however, it decreases after $100 \mathrm{kGy}$. In previous works on the irradiation of FQ using neutrons and $\mathrm{x}$-rays $[18]-[21]$, it was shown that, in some specimens of $\mathrm{FQ}$, the $B_{1}$ band initially increased with increasing radiation exposure, but after reaching a maximum, it started to decrease with further irradiation (this phenomenon is termed radiation bleaching). A detailed analysis of this phenomenon was performed in [20], where radiation bleaching of the $B_{1}$ band was explained in terms of interdependence between the occupancy of $B_{1}$ centres (i.e. the traps responsible for the $B_{1}$ band) and the occupancy of the other defects present in irradiated FQ. We therefore attribute the decrease in absorption of the $B_{1}$ band observed in our sample irradiated at $100 \mathrm{kGy}$ to the same phenomenon already observed in the case of neutron and x-rays irradiation. In any case, the FQ samples stay transparent in the visible range even after the highest dose, as can be visually seen from Fig. $3 b$

The transmittance curves of $\gamma$-irradiated UV-grade PMMA samples are shown in Fig. 2c Upon irradiation, a strong increase in UV absorption occurs, and two absorption bands between 385-425 $\mathrm{nm}$ and 515-580 nm emerge. Increased absorption in the UV has been attributed to increased density of dienes group $(-\mathrm{C}=\mathrm{C}-)_{n}$ due to radiation [22]. The two bands in the visible are due to radiation-induced free radicals acting as colour centres [22]-[24]; $\gamma$-ray irradiation involves scission of $\mathrm{C}=\mathrm{O}, \mathrm{C}-\mathrm{C}, \mathrm{C}-\mathrm{O}-\mathrm{C}$, and $\mathrm{C}-\mathrm{C}-\mathrm{O}$ bonds [22]. It is also evident that radiation-induced optical damage tends to saturate at higher doses (the curves after 50 and $100 \mathrm{kGy}$ are almost overlapping); this phenomenon is due to competition between molecular scission and cross-linking induced by radiation [22]. Previous studies in literature have shown that crosslinking under $\gamma$-ray irradiation occurs at doses $>10 \mathrm{kGy}$, and is initiated by the absorption of water from airborne moisture [22]. Cross-linking occurs between $\mathrm{C}-\mathrm{H}, \mathrm{O}-\mathrm{H}$, and $\mathrm{H}-\mathrm{O}-\mathrm{H}$ bonds (the last two induced by absorbed water molecules) [22]. As a consequence of the aforementioned colour centres, PMMA samples turned yellow upon irradiation (see Fig. 3c).

Finally, the transmittance curves of PC samples are shown in Fig. 2d. Several absorption bands are introduced by radiation in the visible range, the most evident ones being around $\sim 415 \mathrm{~nm}$ and between 550-580 nm. Previous works [25][28] have shown that $\gamma$-ray irradiation of PC leads to chain scissioning and formation of different types of products (like e.g. species containing ortho-quinone groups), acting as colour 


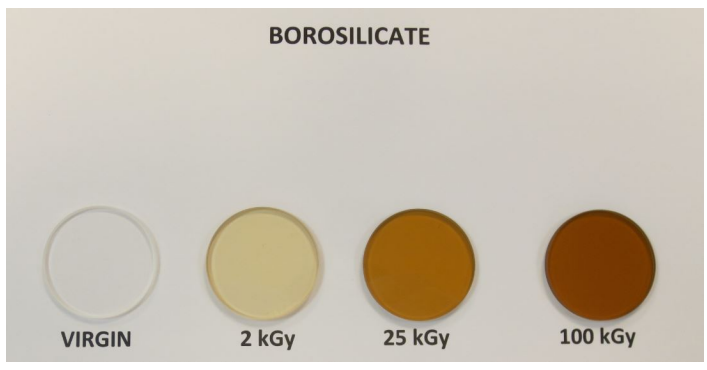

(a)

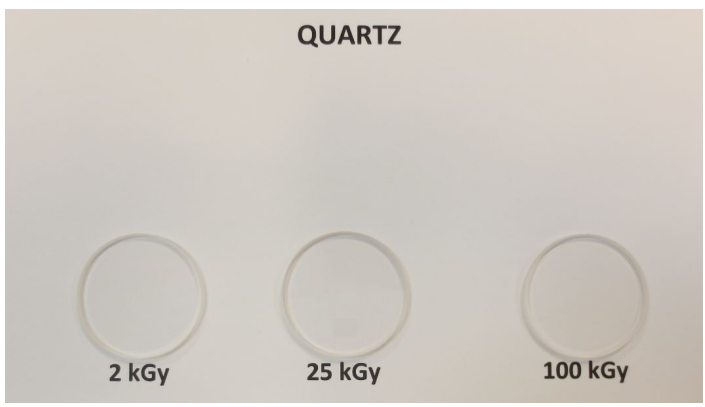

(b)

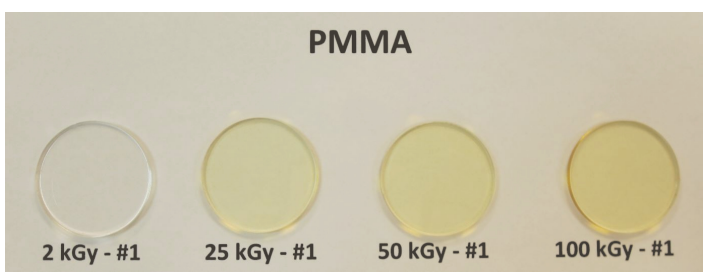

(c)

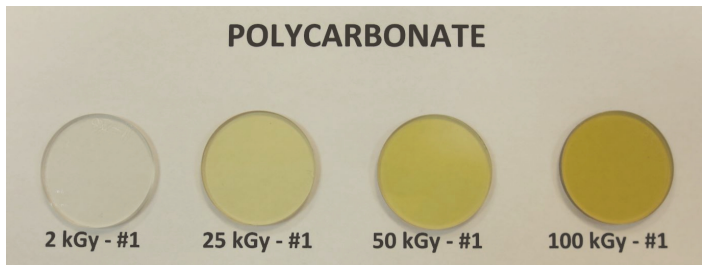

(d)

Fig. 3. Pictures of irradiated samples of: (a) borosilicate, (b) fused quartz, (c) PMMA, (d) polycarbonate.

centres in the visible spectrum. Unlike PMMA, absorption at these radiation-induced bands does not saturate at high doses (conversely, the optical damage continues to increase with dose). A larger reduction in trasmittance is obtained in PC than in PMMA, as also demonstrated by the more intense yellow radiation-induced colouration of the PC samples (see Fig. 3d.

Radiation-induced absorption bands in the considered materials decrease if subjected to thermal treatment with high temperatures (i.e. radiation-induced defects originating these bands can be thermally annealed); in particular, previous experiments have shown that recovery of transmission at radiation-induced bands occurs even at room temperature. For more details on thermal annealing at room temperature in air of borosilicate, we defer to [13], [29]; for quartz, we defer to [30] and references therein; for PMMA and PC, we make reference to [23], [31]. In addition, radiation-induced absorption bands in these materials can also be optically bleached: absorption bands at $210 \mathrm{~nm}$ and $300 \mathrm{~nm}$ in $\gamma$-ray irradiated FQ are known to photobleach under UV light [21]; visible light can bleach radiation-induced absorption bands in both BS [32], [33] and PC [34], [35]; optical bleaching of PMMA presents a more complex behaviour, exhibiting a reduction or an enhancement of the radiation-induced absorption in the UV spectrum depending on the emission wavelength of the light source used for bleaching [36]. Therefore, keeping in mind the application of these materials as optical components for rad-hard lighting systems, a recovery of the transmission properties is to be expected after irradiation as a consequence of thermal annealing (even at room temperature) and, particularly in BS and PC, optical bleaching induced by the white LEDs (for reference, the electroluminescence spectrum of a white GaN LED extends from $400 \mathrm{~nm}$ to $750 \mathrm{~nm}$ ). Nevertheless, in the design of a rad-hard luminaire, the optical components should be chosen based on their transmission properties just after irradiation (i.e. based on the data presented in the paragraphs above), as this would represent the worstcase (most-conservative) scenario. For example, access by human operators into CERN experimental facilities tunnels is prohibited while the particle accelerators are running, owing to the extremely high radiation levels produced by the circulating beams [2]; under such circumstances, the tunnel illumination system is therefore not required to be activated (i.e. lights are off while the accelerators are running). Access to accelerator tunnels is possible only during machine stops, when there is no circulating beam, after a cool down period to allow the residual radiation to decay (typically a few hours from the beam stop, but it can be 30-40 hours for the most radioactive areas). Consequently, the lighting system shall be designed to provide the stipulated minimum illuminance levels just after the accelerator stops, so that the optical materials offering the best performance just after irradiation should be selected for use in rad-hard luminaires.

In conclusion, BS exhibits a significant reduction of visible light transmission even after $2 \mathrm{kGy}$ (corresponding to $\sim 2$ years on the tunnel walls of a typical section of CERN accelerator complex), while FQ retains transparency to visible light even after $100 \mathrm{kGy}$; therefore, BS protective windows in luminaires for radioactive environment should be avoided in favour to FQ components. Visible light transmission in both PMMA and PC is degraded by radiation-induced colour centres, but larger values of absorption are measured in PC samples; consequently PMMA should be specified instead of PC as a component for secondary optics lenses.

\section{B. Diodes}

Current-voltage $(I-V)$ characteristics of $\mathrm{Si}$ and $\mathrm{SiC}$ diodes were measured before and after irradiation with a Keithley 2410 source-meter unit, at room temperature. Measurements of the forward and reverse $I-V$ curves were done in the range $0-1 \mathrm{~A}$, and $-20-0 \mathrm{~V}$, respectively. In the case of $\mathrm{Si}$ bridge rectifiers, all four diodes contained in each package were tested. Equivalent results were obtained for all diodes irradiated in the same batch; for this reason, data of only one 


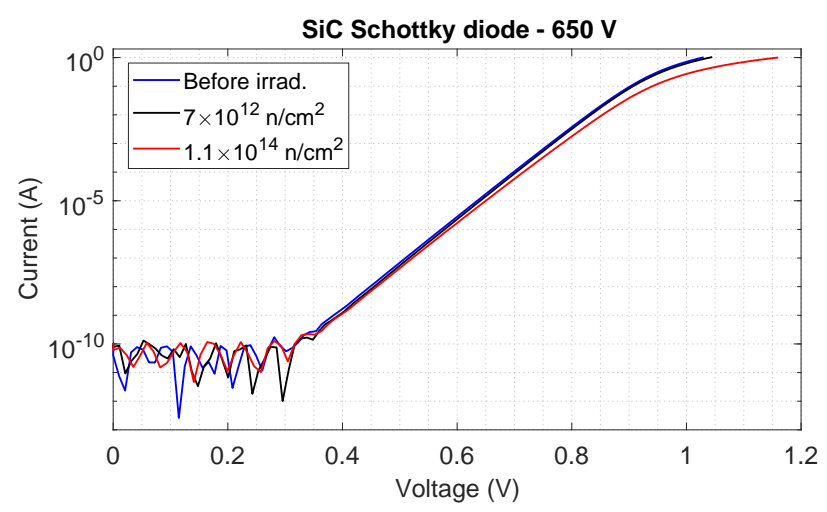

(a)

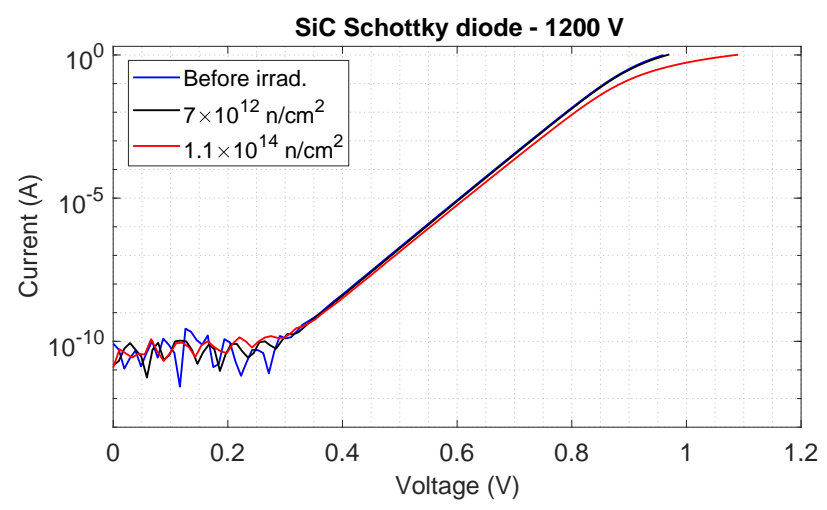

(b)

Fig. 4. $I-V$ characteristics at room temperature of (a) STPSC10H065D and (b) STPSC10H12-Y SiC diodes, before and after irradiation (expressed as $1 \mathrm{MeV}$ neq fluence).

representative sample per fluence is shown. All fluences are given as $1 \mathrm{MeV}$ neq fluences in $\mathrm{Si}$.

Figures $4 \mathrm{a}$ and $4 \mathrm{~b}$ show the forward $I-V$ curves before and after irradiation of $650 \mathrm{~V}$ and $1200 \mathrm{~V} \mathrm{SiC}$ diodes, respectively. The behaviour of irradiated $650 \mathrm{~V}$ and $1200 \mathrm{~V} \mathrm{SiC}$ diodes was found to be similar: degradation after $7 \times 10^{12} \mathrm{n} / \mathrm{cm}^{2}$ is very small, while larger damage is detected after the highest fluence (in particular, for currents above $0.1 \mathrm{~A}$ ). We found that $I-V$ curves of both $650 \mathrm{~V}$ and $1200 \mathrm{~V} \mathrm{SiC}$ diodes before irradiation and after a fluence of $7 \times 10^{12} \mathrm{n} / \mathrm{cm}^{2}$ can be well described by the standard model of an ideal diode with a series resistance [37]:

$$
I=I_{s}\left\{\exp \left[\frac{q\left(V-R_{S} I\right)}{\eta k_{B} T}\right]-1\right\}
$$

where $I_{s}$ is the saturation current, $q$ is the absolute electronic charge, $\eta$ is the ideality factor, $k_{B}$ is the Boltzmann constant, $T$ is the absolute temperature, and $R_{S}$ denotes the series resistance. On the other hand, after the highest fluence, two segments with different slopes are observed in the $I-V$ characteristics instead of a single exponential behaviour as in (1); these two segments represent two different current regimes (i.e. different conduction mechanisms), each characterised by a distinct ideality factor $\eta$. In this case, the $I-V$ curves of SiC diodes irradiated at $1.1 \times 10^{14} \mathrm{n} / \mathrm{cm}^{2}$ can be expressed as:

$$
I= \begin{cases}I_{s_{1}}\left[\exp \left(q V^{\prime} / \eta_{1} k_{B} T\right)-1\right], \quad V<V_{T} \\ I_{s_{2}}\left[\exp \left(q V^{\prime} / \eta_{2} k_{B} T\right)-1\right], \quad V>V_{T}\end{cases}
$$

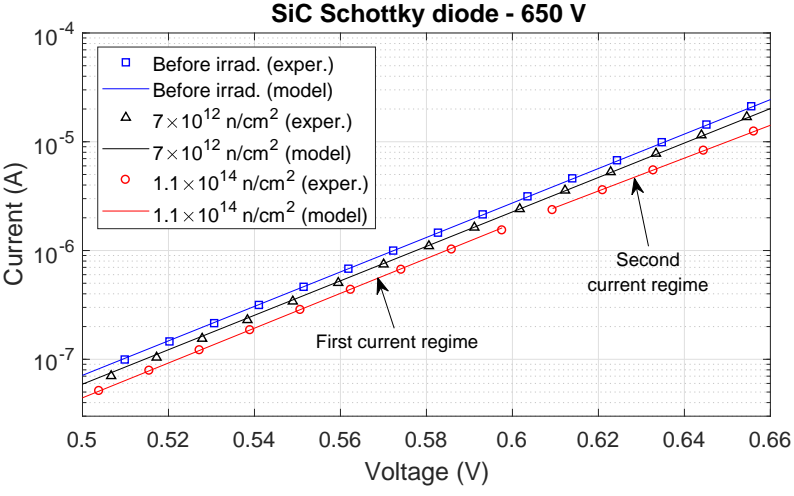

(a)

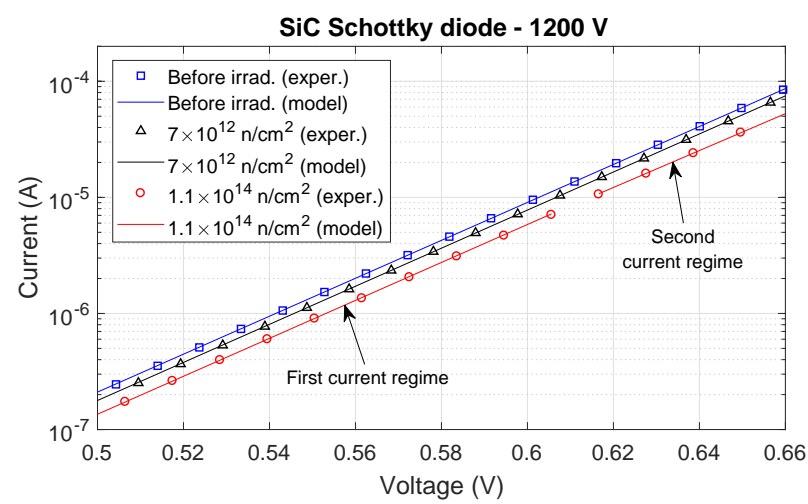

(b)

Fig. 5. Experimental and fitted $I-V$ characteristics at room temperature of (a) STPSC10H065D and (b) STPSC10H12-Y SiC diodes, before and after irradiation (expressed as $1 \mathrm{MeV}$ neq fluence).

where $V^{\prime}=V-R_{S} I$, and $V_{T}$ denotes the voltage at which the transition between the two current regimes occurs. For all $650 \mathrm{~V}$ and $1200 \mathrm{~V} \mathrm{SiC}$ diodes tested, $V_{T}$ is about $0.6 \mathrm{~V}$.

The experimental $I-V$ characteristics of $\mathrm{SiC}$ diodes were fitted to their corresponding models (1) or (2). Before irradiation and after $7 \times 10^{12} \mathrm{n} / \mathrm{cm}^{2}$, the values of $\eta$ and $I_{s}$ in (1) have been extracted through an exponential fit in the current range from $5 \times 10^{-8}$ A to $5 \times 10^{-4}$ A. After $1.1 \times 10^{14} \mathrm{n} / \mathrm{cm}^{2}$, the saturation current and ideality factor for the first (respectively, second) current regime in (2) are obtained by exponential fitting of experimental $I-V$ curves in the current interval from $10^{-9} \mathrm{~A}$ to $10^{-6} \mathrm{~A}$ (respectively, from $5 \times 10^{-6}$ A to $5 \times 10^{-4} \mathrm{~A}$ ). Analogously to [37], $R_{S}$ in (1) and (2) was disregarded while performing these exponential fits, since its effect is negligible in the considered current intervals. $R_{S}$ was then extracted for all curves by fitting the experimental $I-V$ characteristics for $I>0.5 \mathrm{~A}$. Figures $5 \mathrm{a}$ and $5 \mathrm{~b}$ illustrate the experimental and fitted $I-V$ curves for $650 \mathrm{~V}$ and $1200 \mathrm{~V} \mathrm{SiC}$ diodes, respectively; for clarity reasons (i.e. to allow for a distinct representation of all curves), the data is shown only in a limited interval $(0.5-0.66 \mathrm{~V})$, which nevertheless spans across almost three orders of magnitude in current. For $I-V$ curves after $1.1 \times 10^{14} \mathrm{n} / \mathrm{cm}^{2}$, the first and second current regimes are also indicated. As can be seen, fitted and experimental data are in excellent agreement in the represented interval.

Radiation introduces in $4 \mathrm{H}-\mathrm{SiC}$ a wide range of defects, predominantly vacancies and interstitials of $\mathrm{Si}$ and $\mathrm{C}$ atoms, 
and combinations thereof (due to low mobility of primary radiation defects, formation of defect complexes including impurities is limited) [38]. These defects act as compensation and trapping centres, leading to a reduction in free electron density (carrier removal) and hence to greater series resistance $R_{S}$ and lower values of saturation current $I_{s}$ [38]-[40]. Such variations of $I_{s}$ and $R_{S}$ are apparent in Figs. $4 \mathrm{a}$ and $4 \mathrm{~b}$, and can be quantitatively analysed by studying the evolution with increasing radiation exposure of the fitted values of $I_{s}$, $\eta$ and $R_{S}$ in models (1) and (2). The relative variations of these parameters upon irradiation are collected in Table III] the change in saturation current and ideality factor after the highest fluence is computed with respect to values of the first current regime, i.e. $I_{s_{1}}$ and $\eta_{1}$. All variations are computed as $\left(X_{a}-X_{b}\right) / X_{b}$, where $X_{b}$ and $X_{a}$ denote the same quantity before and after irradiation, respectively. After a fluence of $7 \times 10^{12} \mathrm{n} / \mathrm{cm}^{2}$, a reduction in $I_{s}$ of $-16 \%$ and an increase in $R_{S}$ of $8 \%$ w.r.t. pre-irradiated samples is found in $650 \mathrm{~V}$ $\mathrm{SiC}$ diodes; in $1200 \mathrm{~V}$ diodes, $I_{s}$ decreases by $-21 \%$ and $R_{S}$ increases by $9 \%$. In addition, only marginal variations in $\eta$ upon irradiation are found in both types of $\mathrm{SiC}$ diodes $(\eta \approx 1.074$ and $\eta \approx 1.04$ for $650 \mathrm{~V}$ and $1200 \mathrm{~V}$ diodes, respectively, both before and after irradiation). Hence, modest carrier removal is already detected after $7 \times 10^{12} \mathrm{n} / \mathrm{cm}^{2}$, although its impact on the electrical characteristics of the diodes is negligible, as apparent from Figs. 4 and 5 After irradiation at $1.1 \times 10^{14} \mathrm{n} / \mathrm{cm}^{2}, R_{S}$ in $650 \mathrm{~V}$ diodes increases by $\sim 105 \%$ w.r.t. pre-irradiated samples, changing from $95 \mathrm{~m} \Omega$ (before irradiation) to $195 \mathrm{~m} \Omega$ (after $1.1 \times 10^{14} \mathrm{n} / \mathrm{cm}^{2}$ ); $R_{S}$ in $1200 \mathrm{~V}$ diodes degrades even more, increasing by $\sim 143 \%$ from $74 \mathrm{~m} \Omega$ (before irradiation) to $180 \mathrm{~m} \Omega$ (after $1.1 \times 10^{14} \mathrm{n} / \mathrm{cm}^{2}$ ). This increase in $R_{S}$ is responsible for the deviations observed in the $I-V$ curves at currents $I>0.1 \mathrm{~A}$ after the highest fluence (see Figs. $4 \mathrm{a}$ and $4 \mathrm{~b}$ ). The larger increase of $R_{S}$ in $1200 \mathrm{~V}$ devices is attributed to different device geometry (like e.g. larger vertical thickness of the $\mathrm{n}$-drift region). In any case, this increase in $R_{S}$ has only a limited effect on the electrical characteristics of $\mathrm{SiC}$ diodes for currents up to $1 \mathrm{~A}$. The ideality factor of the first region $\left(\eta_{1}\right)$ after $1.1 \times 10^{14} \mathrm{n} / \mathrm{cm}^{2}$ is nearly identical to its corresponding pre-irradiation values in both $650 \mathrm{~V}$ and $1200 \mathrm{~V}$ diodes; in addition, $I_{s_{1}}$ decreases by $-33 \%$ and $-24 \%$ w.r.t. pre-irradiated samples in $650 \mathrm{~V}$ and $1200 \mathrm{~V}$ diodes, respectively. Concerning the second current regime, the values of $\eta_{2}$ are higher than those of $\eta_{1}: \eta_{2}=1.126$ and $\eta_{2}=1.07$ in $650 \mathrm{~V}$ and $1200 \mathrm{~V}$ diodes, respectively, i.e. they

TABLE III

RELATIVE VARIATION OF $I_{s}, \eta$, AND $R_{S}$ IN SIC DIODES UPON HIGH-ENERGY PROTON IRRADIATION

\begin{tabular}{ccccc}
\hline $\begin{array}{c}\text { Voltage } \\
\text { rating }\end{array}$ & $\begin{array}{c}1 \mathrm{MeV} \text { neq } \\
\text { fluence in Si }\end{array}$ & $\begin{array}{c}\Delta I_{s} \\
\left(\Delta I_{s_{1}}\right)\end{array}$ & $\begin{array}{c}\Delta \eta \\
\left(\Delta \eta_{1}\right)\end{array}$ & $\Delta R_{S}$ \\
\hline $650 \mathrm{~V}$ & $7 \times 10^{12} \mathrm{n} / \mathrm{cm}^{2}$ & $-16 \%$ & $+0.03 \%$ & $+8 \%$ \\
$650 \mathrm{~V}$ & $1.1 \times 10^{14} \mathrm{n} / \mathrm{cm}^{2}$ & $-33 \%$ & $+0.13 \%$ & $+105 \%$ \\
$1200 \mathrm{~V}$ & $7 \times 10^{12} \mathrm{n} / \mathrm{cm}^{2}$ & $-21 \%$ & $-0.38 \%$ & $+9 \%$ \\
$1200 \mathrm{~V}$ & $1.1 \times 10^{14} \mathrm{n} / \mathrm{cm}^{2}$ & $-24 \%$ & $+0.27 \%$ & $+143 \%$ \\
\hline
\end{tabular}

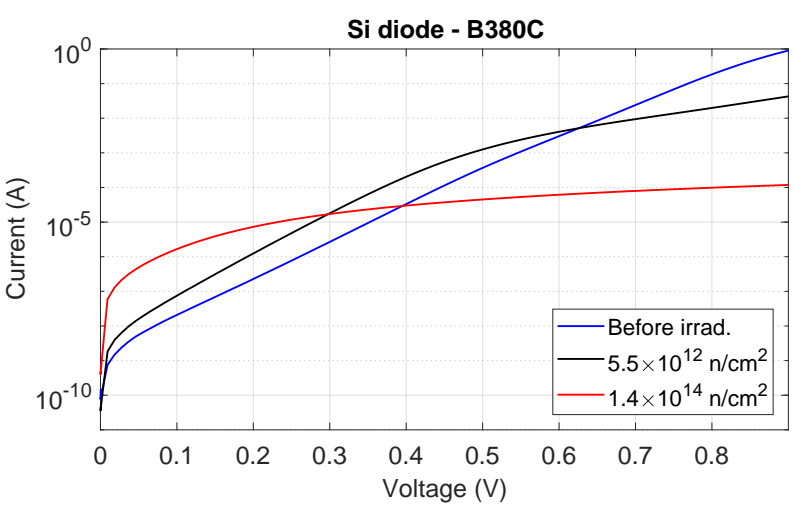

(a)

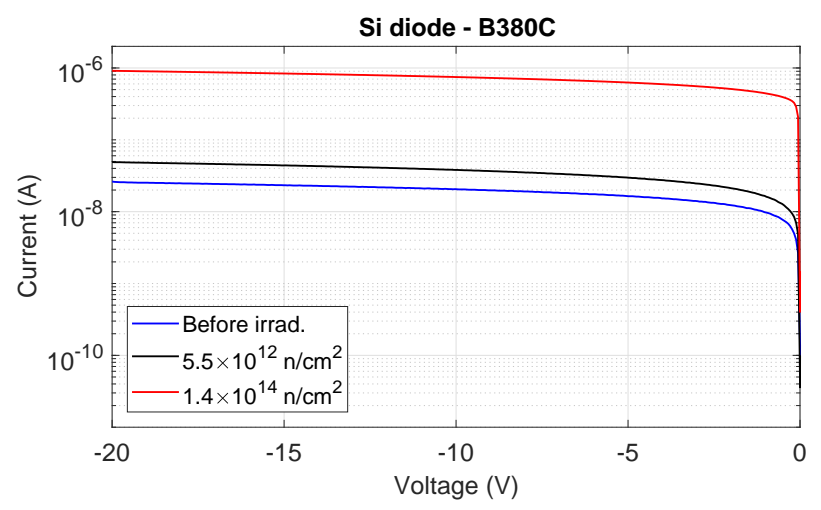

(b)

Fig. 6. (a) Forward and (b) reverse $I-V$ characteristics at room temperature of Si diodes of B380C bridge rectifiers, before and after irradiation (expressed as $1 \mathrm{MeV}$ neq fluence).

are $6.1 \%$ and $3.1 \%$ larger than their corresponding $\eta_{1}$ values; a slight increase of the ideality factor upon proton irradiation of $4 \mathrm{H}-\mathrm{SiC}$ JBS diodes was also found in [37]. We attribute the emergence of the second current regime to radiation-induced defects. In addition, we ascribe the slightly different behaviour of $I_{s_{1}}$ and $\eta_{2}$ between $650 \mathrm{~V}$ and $1200 \mathrm{~V}$ diodes after $1.1 \times 10^{14} \mathrm{n} / \mathrm{cm}^{2}$ to different device geometry and doping characteristics, leading to marginally dissimilar current conduction mechanisms. Our results in terms of device degradation are in good agreement with those in [37], [40], despite use of a diode from a different manufacturer and with different ratings (normalization of radiation damage at various proton energies is done via NIEL curves for $\mathrm{SiC}$ obtained using screened Coulomb potential [41], [42] and considering the effect of nuclear interactions dominating at energies $>100 \mathrm{MeV}$ [43]). Finally, no variations are detected in the reverse bias curves, as expected for Schottky-based diodes and as already noted in literature for similar devices tested at comparable fluences [37], [39]. All these results show that the 4H-SiC JBS diodes under test present only a limited degradation for currents up to 1 A after fluences of $1.1 \times 10^{14} \mathrm{n} / \mathrm{cm}^{2}$, and hence are expected to reliably withstand the radiation environment of a typical section of CERN accelerator tunnels [2] for at least 10 years.

The forward and reverse $I-V$ curves of B380C diodes before and after irradiation are illustrated in Figs. 6a and $6 \mathrm{~b}$, respectively. The four diodes of each bridge exhibited similar characteristics, so only data of individual diodes is 
presented. High-energy proton irradiation introduces numerous defects in $\mathrm{Si}$ including vacancies, interstitials, divacancies, diinterstitials, vacancy-oxygen centres, $\mathrm{C}$ interstitials $\left(\mathrm{C}_{\mathrm{i}}\right)$, complexes of $\mathrm{O}, \mathrm{C}_{\mathrm{i}}, \mathrm{H}$ and $\mathrm{Si}$ vacancies and interstitials, as well as vacancy clusters [44]. These defects act as generationrecombination centres, traps or compensation centres, resulting in increased recombination current at low forward voltages, and increased series resistance due to carrier removal [4], [39], [45]. These effects are clearly observed in Fig. 6a. An increase of generation current at reverse bias is also measured: current at $-20 \mathrm{~V}$ increases from $2.6 \times 10^{-8} \mathrm{~A}$ before irradiation to $4.9 \times 10^{-8} \mathrm{~A}$ after $5.5 \times 10^{12} \mathrm{n} / \mathrm{cm}^{2}$, and to $9.1 \times 10^{-7} \mathrm{~A}$ after $1.4 \times 10^{14} \mathrm{n} / \mathrm{cm}^{2}$ (see Fig. $6 \mathrm{~b}$ ). It is worth noting that Si diodes exhibit significant degradation at fluences more than an order of magnitude lower than SiC JBS diodes.

\section{Conclusions}

Transmission spectra of commercial-grade BS, FQ, PMMA, and PC samples irradiated with $\gamma$-rays up to $100 \mathrm{kGy}$ are presented, and the degradation mechanism of each element is discussed. The obtained results indicate that, in terms of retained transparency upon irradiation, FQ is the most appropriate material for windows in rad-hard LED luminaires, while BS should be avoided; moreover, PMMA should be preferred over PC for secondary optics components. In addition, a Si diode bridge and a SiC JBS diode are tested using $24 \mathrm{GeV} / c$ protons, and radiation effects on both devices are discussed; the SiC JBS diodes measured were more than one order of magnitude more resistant than $\mathrm{Si}$ diodes, and therefore should be employed in future power supplies for rad-hard LED lights. In particular, the obtained results show that $\mathrm{SiC}$ JBS diodes and samples of FQ and PMMA exhibit no or limited degradation after radiation exposure levels equivalent to 10 years on the tunnel wall of a typical section of CERN accelerator complex, thus meeting the requirements on the expected lifetime of the rad-hard LED luminaires for CERN tunnels.

\section{ACKNOWLEDGMENT}

The authors gratefully acknowledge Giuseppe Pezzullo (CERN) and Federico Ravotti (CERN) for performing sample irradiation and assistance at IRRAD facility, Elisa Guillermain (CERN) and Sophie Rouif (Ionisos) for managing the $\gamma$-ray irradiation at Ionisos, and Thomas Schneider (CERN) for providing the spectrophotometer and assistance at the Thin Film and Glass Laboratory (CERN).

\section{REFERENCES}

[1] J. D. Devine and A. Floriduz, "Radiation hardening of LED luminaires for accelerator tunnels," in Proc. 16th Eur. Conf. Rad. Effects on Components and Systems (RADECS), Bremen (Germany). IEEE, 2016, pp. 1-6, https://doi.org/10.1109/RADECS.2016.8093210

[2] J. P. De Carvalho Saraiva and M. Brugger, "Radiation environments and their impact at the CERN's injector chain," CERN, ATS Note 2015-0042, Dec. 2015, https://cds.cern.ch/record/2114889

[3] A. Floriduz and J. D. Devine, "Modelling of proton irradiated GaNbased high-power white light-emitting diodes," Jpn. J. Appl. Phys., vol. 57, no. 8, p. 080304, 2018, https://doi.org/10.7567/JJAP.57.080304
[4] T. Bager, J. Casas, B. Palan, and M. Rodriguez, "Validation of switching power supplies, diode bridges, and conditioners for pressure sensors," CERN, EDMS document 1226409, 2002, https://edms.cern.ch/ document/1226409/1

[5] Vishay General Semiconductor, "Glass passivated single-phase bridge rectifier," B380C Datasheet, [Revised Jul. 2013], https://www.vishay. com/docs/88501/b40c1500g.pdf

[6] - "Glass passivated single-phase bridge rectifier," GBU8K Datasheet, [Revised Apr. 2015], https://www.vishay.com/docs/88616/ gbu8a.pdf

[7] STMicroelectronics, "New generation of 650 V $\mathrm{SiC}$ diodes," Application note AN4242, [Revised May 2013], https://www.st.com/resource/en/application_note/dm00075656-newgeneration-of-650-v-sic-diodes-stmicroelectronics.pdf

[8] S. Rouif, "Radiation cross-linked polymers: Recent developments and new applications," Nucl. Instrum. Meth. Phys. Res. B, vol. 236, no. 1-4, pp. 68-72, 2005, https://doi.org/10.1016/j.nimb.2005.03.252

[9] F. Ravotti, B. Gkotse, M. Moll, and M. Glaser, "IRRAD: The new 24 $\mathrm{GeV} / \mathrm{c}$ proton irradiation facility at CERN," in Proc. 12th Int. Topical Meeting Nucl. Applications of Accelerators (AccApp), vol. 15, 2015, pp. 182-187, http://cds.cern.ch/record/2237333

[10] I. Mateu, M. Moll, E. Curras, F. Ravotti, H. Neugebauer, and M. Glaser, "NIEL hardness factor determination for the new proton irradiation facility at CERN," CERN, Tech. Rep. AIDA-2020-SLIDE-2016-002, 2016, https://cds.cern.ch/record/2162852

[11] A. Lebedev, A. Veinger, D. Davydov, V. Kozlovski, N. Savkina, and A. Strel'chuk, "Doping of n-type $6 \mathrm{H}-\mathrm{SiC}$ and $4 \mathrm{H}-\mathrm{SiC}$ with defects created with a proton beam," J. Appl. Phys., vol. 88, no. 11, pp. 6265 6271, 2000, https://doi.org/10.1063/1.1309055

[12] J. Doyle, M. K. Linnarsson, P. Pellegrino, N. Keskitalo, B. Svensson, A. Schöner, N. Nordell, and J. Lindström, "Electrically active point defects in n-type 4H-SiC," J. Appl. Phys., vol. 84, no. 3, pp. 13541357, 1998, https://doi.org/10.1063/1.368247

[13] Q. Wang, Z. Zhang, H. Geng, C. Sun, D. Yang, S. He, and Z. Hu, "Radiation-induced damage and recovery effects in GG17 glass irradiated by $1 \mathrm{MeV}$ electrons," Nucl. Instrum. Meth. Phys. Res. B, vol. 281, pp. 1-7, 2012, https://doi.org/10.1016/j.nimb.2012.04.010

[14] Q. Wang, H. Geng, S. He, D. Yang, Z. Zhang, X. Qin, and Z. Li, "Effects of $80 \mathrm{keV}$ proton radiation on the optical properties and microstructure of type-GG17 glass as rubidium lamp envelope," Nucl. Instrum. Meth. Phys. Res. B, vol. 267, no. 15, pp. 2489-2494, 2009, https://doi.org/10. 1016/j.nimb.2009.06.006

[15] Q. Wang, H. Geng, C. Sun, X. Li, H. Zhao, W. Liu, J. Xiao, and Z. Hu, "Radiation effects on optical and structural properties of GG17 glasses induced by $170 \mathrm{keV}$ electrons and protons," J. Appl. Phys., vol. 119, no. 2, p. 023103, 2016, https://doi.org/10.1063/1.4939097

[16] C. D. Marshall, J. A. Speth, and S. A. Payne, "Induced optical absorption in gamma, neutron and ultraviolet irradiated fused quartz and silica," $J$. Non-Cryst. Solids, vol. 212, no. 1, pp. 59-73, 1997, https://doi.org/10. 1016/S0022-3093(96)00606-0

[17] M. León, P. Martín, A. Ibarra, and E. Hodgson, "Gamma irradiation induced defects in different types of fused silica," J. Nucl. Mater, vol. 386, pp. 1034-1037, 2009, https://doi.org/10.1016/j.jnucmat.2008.12.232

[18] M. Guzzi, M. Martini, A. Paleari, F. Pio, A. Vedda, and C. Azzoni, "Neutron irradiation effects in amorphous $\mathrm{SiO}_{2}$ : optical absorption and electron paramagnetic resonance," J. Phys. Condens. Matter, vol. 5, no. 43, p. 8105 , 1993, https://doi.org/10.1088/0953-8984/5/43/022

[19] E. Mitchell and E. Paige, "The optical effects of radiation induced atomic damage in quartz," Philos. Mag., vol. 1, no. 12, pp. 1085-1115, 1956, https://doi.org/10.1080/14786435608238193

[20] E. Paige, "The kinetics of colour centre formation in quartz," Philos. Mag., vol. 2, no. 19, pp. 864-876, 1957, https://doi.org/10.1080/ 14786435708242725

[21] M. Levy and J. Varley, "Radiation induced colour centres in fused quartz," Proc. Phys. Soc., Sect. B, vol. 68, no. 4, p. 223, 1955 , https://doi.org/10.1088/0370-1301/68/4/304

[22] V. Rai, C. Mukherjee, and B. Jain, "UV-Vis and FTIR spectroscopy of gamma irradiated polymethyl methacrylate," Indian J. Pure Appl. Phys., vol. 55, no. 11, pp. 775-785, 2017, http://op.niscair.res.in/index.php/ IJPAP/article/view/15541

[23] R. Clough, K. Gillen, G. Malone, and J. Wallace, "Color formation in irradiated polymers," Radiat. Phys. Chem., vol. 48, no. 5, pp. 583-594, 1996, https://doi.org/10.1016/0969-806X(96)00075-8

[24] K.-P. Lu, S. Lee, and C. P. Cheng, "Transmittance in irradiated poly (methyl methacrylate) at elevated temperatures," J. Appl. Phys., vol. 88, no. 9, pp. 5022-5027, 2000, https://doi.org/10.1063/1.1316792 
[25] T. Sharma, S. Aggarwal, A. Sharma, S. Kumar, V. Mittal, P. Kalsi, and V. Manchanda, "Modification of optical properties of polycarbonate by gamma irradiation," Radiat. Eff. Defects Solids, vol. 163, no. 2, pp. 161167, 2008, https://doi.org/10.1080/10420150701688503

[26] D. Sinha, K. Sahoo, U. Sinha, T. Swu, A. Chemseddine, and D. Fink, "Gamma-induced modifications of polycarbonate polymer," Radiat. Eff. Defects Solids, vol. 159, no. 10, pp. 587-595, 2004, https://doi.org/10. 1080/10420150412331330539

[27] A. Factor, J. Carnahan, S. Dorn, and P. Van Dort, "The chemistry of $\gamma$-irradiated bisphenol-A polycarbonate," Polym. Degrad. Stab., vol. 45, no. 1, pp. 127-137, 1994, https://doi.org/10.1016/0141-3910(94)901880

[28] A. Factor and P. Donahue, "The use of ${ }^{31} \mathrm{P}$ NMR to identify color bodies in $\gamma$-irradiated bisphenol-A polycarbonate," Polym. Degrad. Stab., vol. 57, no. 1, pp. 83-86, 1997, https://doi.org/10.1016/S01413910(96)00216-9

[29] A. Gusarov, D. Doyle, L. Glebov, and F. Berghmans, "Comparison of radiation-induced transmission degradation of borosilicate crown optical glass from four different manufacturers," in Proc. SPIE 5897, Photonics for Space Environments $X$. International Society for Optics and Photonics, 2005, p. 58970I, https://doi.org/10.1117/12.619199

[30] S. Agnello and L. Nuccio, "Thermal stability of gamma-irradiationinduced oxygen-deficient centers in silica," Phys. Rev. B, vol. 73, no. 11, p. 115203, 2006, https://doi.org/10.1103/PhysRevB.73.115203

[31] R. Clough, G. Malone, K. Gillen, J. Wallace, and M. Sinclair, "Discoloration and subsequent recovery of optical polymers exposed to ionizing radiation," Polym. Degrad. Stab., vol. 49, no. 2, pp. 305-313, 1995, https://doi.org/10.1016/0141-3910(95)87013-X

[32] M. J. Treadaway, B. C. Passenheim, and B. D. Kitterer, "Transient radiation effects in optical materials," Intelcom Rad Tech, Tech Rep. SAMSO-TR-75-174, 1975, https://apps.dtic.mil/dtic/tr/fulltext/u2/ a013922.pdf

[33] M. Treadaway, B. Passenheim, B. Kitterer, and P. Schall, "Radiation coloration and bleaching of glass," IEEE Trans. Nucl. Sci., vol. 23, no. 6, pp. 1820-1825, 1976, https://doi.org/10.1109/TNS.1976.4328584

[34] C. Lundy, M. Licata, E. Haag, and S. Krishnan, "Methods of color stabilization in radiation-sterilized polycarbonate," in Proc. SPE ANTEC 1988. Society of Plastics Engineers, 1988, pp. 1348-1351.

[35] N. Hermanson and J. Steffen, "The physical and visual property changes in thermoplastic resins after exposure to high energy sterilization-gamma versus electron beam," in Proc. SPE ANTEC 1993. Society of Plastics Engineers, 1993, pp. 784-784.
[36] K. Chadwick, "The effect of light exposure on the optical density of irradiated clear polymethylmethacrylate," Phys. Med. Biol., vol. 17, no. 1, pp. 88-93, 1972, https://doi.org/10.1088/0031-9155/17/1/010

[37] R. D. Harris, A. J. Frasca, and M. O. Patton, "Displacement damage effects on the forward bias characteristics of SiC Schottky barrier power diodes," IEEE Trans. Nucl. Sci., vol. 52, no. 6, pp. 2408-2412, 2005, https://doi.org/10.1109/TNS.2005.860730

[38] F. Nava, G. Bertuccio, A. Cavallini, and E. Vittone, "Silicon carbide and its use as a radiation detector material," Meas. Sci. Technol., vol. 19, no. 10, p. 102001, 2008, https://doi.org/10.1088/0957-0233/19/ $10 / 102001$

[39] Z. Luo, T. Chen, J. D. Cressler, D. C. Sheridan, J. R. Williams, R. A. Reed, and P. W. Marshall, "Impact of proton irradiation on the static and dynamic characteristics of high-voltage 4H-SiC JBS switching diodes," IEEE Trans. Nucl. Sci., vol. 50, no. 6, pp. 1821-1826, 2003, https: //doi.org/10.1109/TNS.2003.821806

[40] V. Kozlovski, A. Lebedev, M. Levinshtein, S. Rumyantsev, and J. Palmour, "Electrical and noise properties of proton irradiated $4 \mathrm{H}-\mathrm{SiC}$ Schottky diodes," J. Appl. Phys., vol. 123, no. 2, p. 024502, 2018, https://doi.org/10.1063/1.5018043

[41] S. R. Messenger, E. A. Burke, M. A. Xapsos, G. P. Summers, R. J. Walters, I. Jun, and T. Jordan, "NIEL for heavy ions: An analytical approach," IEEE Trans. Nucl. Sci., vol. 50, no. 6, pp. 1919-1923, 2003, https://doi.org/10.1109/TNS.2003.820762

[42] K. Lee, T. Ohshima, A. Saint, T. Kamiya, D. Jamieson, and H. Itoh, "A comparative study of the radiation hardness of silicon carbide using light ions," Nucl. Instrum. Meth. Phys. Res. B, vol. 210, pp. 489-494, 2003, https://doi.org/10.1016/S0168-583X(03)01096-6

[43] S. M. Khanna, D. Estan, L. S. Erhardt, A. Houdayer, C. Carlone, A. Ionascut-Nedelcescu, S. R. Messenger, R. J. Walters, G. P. Summers, J. H. Warner, and I. Jun, "Proton energy dependence of the light output in gallium nitride light-emitting diodes," IEEE Trans. Nucl. Sci., vol. 51, no. 5, pp. 2729-2735, 2004, https://doi.org/10.1109/TNS.2004.835097

[44] G. Davies, S. Hayama, L. Murin, R. Krause-Rehberg, V. Bondarenko, A. Sengupta, C. Davia, and A. Karpenko, "Radiation damage in silicon exposed to high-energy protons," Phys. Rev. B, vol. 73, no. 16, p. 165202, 2006, https://doi.org/10.1103/PhysRevB.73.165202

[45] H. Spieler, "Introduction to radiation-resistant semiconductor devices and circuits," in AIP Conf. Proc., vol. 390, no. 1. AIP, 1997, pp. 23-49, https://doi.org/10.1063/1.52282 